\title{
DIREITO DO MAR: NOTAS SOBRE UMA NARRATIVA DE VALORES
}

\author{
LAW OF THE SEA: NOTES ABOUT A NARRATION OF VALUES
}

Sergio Eduardo Moreira Lima*

\begin{abstract}
Resumo:
Este artigo tem sua origem na palestra Direito do Mar. Diálogo entre Diplomacia e Academia, que proferi na sessão de abertura do I Congresso Brasileiro de Direito do Mar, em homenagem a Vicente Marotta Rangel, na Universidade de São Paulo, em 3 de dezembro de 2014. Destaquei, na ocasião, a importância da participação do Brasil na negociação da Convenção de Montego Bay de 1982, bem como do processo de construção paulatina de princípios que inspiram e devem orientar a política externa brasileira.
\end{abstract}

Palavras-chave: Direito do Mar. Homenagem a Vicente Marotta Rangel. Convenção de Montego Bay.

\begin{abstract}
:
This paper is based on a lecture entitled "Law of the Sea. Dialogues between diplomacy and academy", at the opening of the Ist Brazilian Congress on Law of the Sea, as as tribute to Professor Vicente Marotta Rangel, at the University of Sao Paulo in December $3^{\text {rd }}$, 2014. I focused the contribution of Brazil to the Convention of Montego Bay in 1982, as well as the continuing process of creation of principles which inspire and must lead the Brazilian foreign policy.
\end{abstract}

Keywords: Law of the Sea. Tribute to Vicente Marotta Rangel. Convention of Montego Bay.

Creio que o convite que recebi da Associação Brasileira de Direito Internacional Público para debater o tema entre respeitados especialistas no campo do Direito do Mar deveu-se ao fato de que, como Presidente da Fundação Alexandre de Gusmão, tivera a oportunidade de apresentar o livro "Reflexões sobre a Convenção do Direito do Mar", editado pela FUNAG. ${ }^{1}$ Trata-se de coletânea de ensaios de mestres da matéria, entre os quais o próprio Professor Emérito da USP Marotta Rangel, onde busquei inserir a temática no contexto dos esforços do Brasil em prol do fortalecimento do sistema das Nações Unidas, da defesa do multilateralismo e da democratização das relações internacionais. Em palestra posterior na Escola de Guerra Naval, abordei a Convenção do Mar pela ótica da pesquisa em relações internacionais no contexto da História Diplomática Brasileira e da necessidade de interação crescente da diplomacia com a sociedade.

Embaixador, Presidente da Fundação Alexandre de Gusmão (FUNAG).

BEIRÃO, André Panno; ALVES PEREIRA, Antônio Celso. Reflexões sobre a Convenção do Direito do Mar. Brasília: Fundação Alexandre de Gusmão, 2014. 
Assim como na palestra magna, procurei fazer convergir esses dois enfoques e transitar brevemente pelo desafio da extensão da plataforma continental brasileira, tema de grande atualidade, objeto de outro livro recém-publicado pela FUNAG, bem como pela ideia, ainda pouco debatida, acerca do interesse brasileiro no Ártico.

Ao final, citarei testemunho eloquente do chefe de Estado da maior potência global, cujo Senado ainda não ratificou a Convenção do Direito do Mar, a respeito da importância da adesão universal àquele instrumento para a solução pacífica das controvérsias e a manutenção da paz e da segurança internacional.

Ao longo deste ensaio pretendo estimular a reflexão sobre uma narrativa de valores, ${ }^{2}$ que poderá representar perspectiva distinta para a compreensão das relações internacionais. Espero que contribua para elucidar o dilema da legitimidade no ordenamento internacional e instigar a necessidade de equilíbrio e coerência entre os valores universais defendidos internamente e sua projeção no mundo, sobretudo no caso de um país democrático, vocacionado para a paz, para o desenvolvimento e a cooperação internacional.

\section{Diálogo Diplomacia e Academia}

Num mundo globalizado, caracterizado por elevado grau de interdependência entre os Estados, somos cada vez mais afetados por decisões tomadas fora de nossos países. Daí a importância do conhecimento das relações internacionais, do Direito das Gentes e da promoção do diálogo entre Diplomacia e Academia. Apesar das diferenças, o trabalho e a pesquisa dessas duas instituições podem complementar-se para reforçar conceitos e doutrinas, desenvolver narrativas, bem como consolidar pensamento próprio sobre o tema. A interação entre diplomacia e academia não deve perder de vista o imperativo ético da consistência entre a política e os valores e princípios em que se baseia a ação do Estado. ${ }^{3}$

Ao promover o diálogo com a sociedade, a FUNAG busca cumprir com sua missão pedagógica de formar no País opinião pública sensível aos problemas da convivência internacional, contribuir para a transparência e legitimidade da política externa

2 Na acepção usada neste ensaio, valores correspondem às crenças fundamentais de um povo, aos princípios que utiliza para definir o que é certo, bom e justo. Representam os padrões morais, que inspiram e fornecem orientação quando se busca diferenciar o certo do errado, o bom do mau. Rokeach define valor como uma crença duradoura em um modelo específico de conduta ou estado de existência, que é pessoalmente ou socialmente adotado, e que está embasado em uma conduta preexistente. Assim, os valores podem expressar os sentimentos e os propósitos de uma vida, tornando-se muitas vezes a base das lutas, dos compromissos e do comportamento individual e coletivo. Sem valores morais não é possível estruturar uma sociedade democrática. ROKEACH, Milton. The nature of human values. New York: The Free Press, 1973.

3 MOREIRA LIMA, Sergio Eduardo. Diplomacia e Academia: o IPRI, Instrumento de Política Externa. Política Externa, v. 23, n. 2, São Paulo, 2014. p. 75-82. 
brasileira e para enriquecer o universo conceitual e empírico das relações internacionais e de disciplinas correlatas, como a do Direito Internacional Público. ${ }^{4}$

Questão central com que se defronta o Estado reside na capacidade de responder a desafios externos de maneira a salvaguardar perante a comunidade das nações seus interesses, crenças e tradições. O conhecimento das relações internacionais, assim como do Direito, concorre para a qualidade da mensagem que transmite ao mundo, bem como para a correção e a autonomia com que é formulada sua política exterior. A fim de avaliar o exercício de tais prerrogativas públicas, cumpre revisitar a trajetória percorrida pelo Estado na formação de sua identidade no cenário internacional. Com isso, pode-se averiguar se sua política externa é acidental e reativa, fruto do acaso e reflexo apenas de decisões tomadas por outros povos, ou, ao contrário, se tem contribuído para a gênese de uma nação politicamente organizada, livre e soberana, respeitada por seus valores. São estes o penhor de coerência e consistência da diplomacia e da preservação de suas credenciais numa perspectiva histórica.

$\mathrm{Na}$ maior parte de sua História, o Brasil tem estado em sintonia com as grandes correntes do pensamento contemporâneo, ainda que ajustadas a uma leitura e a um tempo próprios e a condicionantes locais. Trata-se de uma avaliação que pode ser aprimorada e enriquecida com o concurso da academia. $\mathrm{O} 40^{\circ}$ aniversário da criação, na Universidade de Brasília, do primeiro curso de Relações Internacionais no País talvez se preste não apenas ao exame do que a disciplina significa para a inteligência brasileira, como também à análise de uma narrativa que acompanhe e interprete o pensamento diplomático.

O mérito desse exercício estaria em demonstrar aos estudantes e à sociedade em geral a importância da pesquisa axiológica nas ciências sociais e jurídicas, bem como os princípios e aspirações que distinguem o Brasil nessa evolução. É a partir dela que se poderá consolidar visão ampla sobre o significado da inserção do País no mundo (Weltanschauung). A academia tem papel crítico a desempenhar também na formação por parte da sociedade de um juízo profundo quanto ao legado construído por sua chancelaria na formulação e execução da política externa e na preservação da memória diplomática. A percepção social contribui para melhor identificar a posição do Brasil perante a comunidade das nações e assegurar a adequação e a consistência dos rumos de suas ações externas.

\footnotetext{
$4 \quad$ A FUNAG tem publicado importantes obras nesse campo, entre elas, o clássico Direito das Gentes, de Vattel, bem como o Tratado de Direito Internacional Público, de Hildebrando Accioly, em três volumes, com o prefácio do Professor Paulo Borba Casella.
} 
Princípios e valores da política externa brasileira

A definição desses parâmetros éticos e teleológicos tem seu marco na referência conceitual e legal dos princípios que orientam as relações internacionais do País inscritos no art. $4^{\circ}$ de sua Carta Magna: independência nacional, prevalência dos direitos humanos, autodeterminação dos povos, não-intervenção, igualdade entre os Estados, defesa da paz, solução pacífica dos conflitos, repúdio ao terrorismo e ao racismo, cooperação entre os povos para o progresso da humanidade, concessão de asilo político, além da integração latino-americana. Restaria, assim, após a identificação desses princípios constitucionais, verificar o começo de sua evolução e a origem dessas aspirações na perspectiva da História Diplomática Brasileira.

Em 2013, a Fundação Alexandre de Gusmão organizou um projeto que contribui para uma narrativa de valores da política externa e das relações internacionais do Brasil. Dele resultaram três volumes sobre o Pensamento Diplomático Brasileiro, em que seus organizadores nutriam a ambição de tornar aquele trabalho o primeiro passo para outras pesquisas e debates sobre personagens e circunstâncias. ${ }^{5}$ Defendiam a noção de que a diplomacia brasileira dispõe, historicamente, de ideias, ou de um pensamento, a sustentar-lhe a ação. ${ }^{6}$ A obra, que contou com a participação de profissionais do Itamaraty e professores, com notório conhecimento da matéria, fez criteriosa seleção de vultos que influíram no pensamento diplomático nacional. Creio que em todos poder-se-iam encontrar referências que justificassem sua inclusão numa narrativa como a pretendida neste artigo. Diante, porém, das limitações impostas pela natureza do exercício, escolhi para representá-los apenas uns poucos formuladores da política externa e estadistas que deixaram marcas profundas na formação do pensamento diplomático brasileiro.

Talvez o ponto de partida nesse processo de edificação conceitual e doutrinária possa ser encontrado antes mesmo da Independência num personagem que iria marcar a dimensão do espaço territorial brasileiro. Trata-se do diplomata Alexandre de Gusmão, nascido em Santos, que se notabilizou pelos serviços prestados à Corte de D. João V, em importantes negociações com a Coroa Espanhola. Foi o responsável por pesquisar no Direito Privado Romano o princípio do uti possidetis e por transplantá-lo para o Direito das Gentes no Tratado de Madri de 1750, que deu ao território brasileiro expressão mais próxima à que hoje ostenta, em comparação aos limites fixados no instrumento até então vigente, o Tratado de Tordesilhas (1494). Observe-se que o preceito só se aplicava à posse

$5 \quad$ PIMENTEL, José Vicente de Sá (Org.). Pensamento diplomático brasileiro. Formuladores e agentes de política externa. 1750-1964. Brasília: Fundação Alexandre de Gusmão, 2013. p. 8-9.

6 Id. Ibid., em, p. 15. Artigo de Paulo Roberto de Almeida. "Pensamento Diplomático Brasileiro: Introdução metodológica às ideias e ações de alguns dos seus representantes". 
pela ocupação mediante povoamento efetivo e não pela conquista militar. $\mathrm{O}$ feito de Gusmão consagrou os valores da pesquisa, do conhecimento, da Diplomacia e do Direito num mundo onde prevalecia o poder da força. ${ }^{7}$

Sem dúvida, o valor mais alto alcançado pelo Brasil em sua História foi o da Independência, o do direito a aspirar, como nação, a uma identidade comum, escolher suas próprias instituições legais e políticas e quem vai representá-lo ou governá-lo, de forma soberana, sem condicionamentos à autoridade externa. Considerado patrono da Independência e nomeado primeiro chanceler brasileiro, José Bonifácio logrou, em sua singular e acidentada trajetória política, o reconhecimento da autonomia do País pela comunidade das nações. Defendeu ainda outros valores e princípios, como o deslocamento do eixo da política externa brasileira para o entorno regional, sobretudo na Bacia do Prata; a criação de uma comunidade de nações lusófonas; a integração territorial (inclusive com a ideia ainda incipiente do estabelecimento da capital no centro geográfico do País); a integração social mediante a abolição da escravidão e a absorção dos elementos negro e indígena na sociedade brasileira. ${ }^{8}$

Além desses propósitos, que antecipavam, em alguns casos, o que constitui atualmente a noção de direitos humanos e, até mesmo, o conceito de boa vizinhança, Bonifácio consagrou-se na defesa de estratégia exitosa do reconhecimento da Independência do País pelas potências da época, respeitada a unidade territorial do Brasil e sua soberania plena. Fez observar a preservação da autonomia decisória do Estado em relação aos centros internacionais, valendo-se da importância geoestratégica do País e do seu peso como mercado exportador e consumidor como fator de barganha e de poder. Bonifácio inaugurou a prática que se tornaria característica da diplomacia brasileira de apresentar o Brasil acompanhado sempre de seu enorme potencial e não reduzido a suas limitações conjunturais. José Bonifácio fez por merecer, pelo vigor e alcance de suas ideias e por sua visão de estadista, lugar próprio no panteão dos heróis nacionais.

Dentre as personalidades que marcaram o pensamento diplomático brasileiro, o vulto maior é, sem dúvida, o Barão do Rio Branco. Sua sensibilidade aos desafios que enfrentava o Brasil muito se beneficiou da experiência do pai, José Maria da Silva Paranhos, o Visconde do Rio Branco, considerado o maior estadista do Segundo Reinado, Presidente que foi do Conselho de Ministros após o término da Guerra da Tríplice Aliança, momento de defesa da soberania. Creio que o Visconde mereceria pesquisa aprofundada nesta exposição para fixar os valores que promoveu como diplomata, chanceler e estadista.

CORTESÃO, Jaime. Alexandre de Gusmão. Brasília: Fundação Alexandre de Gusmão, 2011.

8 ANJOS, João Alfredo dos. José Bonifácio, primeiro chanceler do Brasil. Brasília: Fundação Alexandre de Gusmão, 2008. 
O foco, no entanto, neste exercício exploratório permanece com o Barão do Rio Branco, que, após longa carreira diplomática, inclusive no exterior, serviu como chanceler da República, de 1902 a 1912. Logrou inspirar narrativa própria em torno de conceitos e de valores consagrados com o êxito que obteve na negociação das fronteiras do Brasil. ${ }^{9}$ Com habilidade e conhecimento de causa, destacou-se nas tratativas que garantiram ao País o reconhecimento e a legitimidade de seu vasto espaço territorial. Com base no Direito Internacional, especialmente no campo da solução pacífica das controvérsias, consolidou extraordinário legado para o Brasil, o qual representa também marco de estabilidade hemisférica e de boa vizinhança. Fez prevalecer interesses nacionais estratégicos em meio a situações complexas envolvendo poderes assimétricos numa fase de transição geopolítica entre a Europa e os Estados Unidos da América. Sua obra tornou-o não apenas respeitado erudito e diplomata, mas igualmente estrategista, estadista e herói nacional, fato que distingue a diplomacia brasileira e os ideais a que tem servido historicamente.

Ao superar a herança de conflito na Bacia do Prata e conferir prioridade à cooperação e à solução negociada das disputas, Rio Branco criou mais do que um estilo de fazer diplomático, defendeu e colocou em prática valores de uma cultura de paz. Esses valores se converteram em princípios que se tornaram fundamentos de um paradigma da política externa brasileira, inspirado no primado do direito e da diplomacia, na nãoingerência, na boa vizinhança, na solução pacífica das controvérsias, na igualdade soberana dos Estados. Rio Branco deu expressão internacional ao sentir do povo, à moderação, à solidariedade e à afetividade. Consagrou a política externa como instrumento de defesa da soberania e da consecução do interesse nacional.

Na verdade, José Maria da Silva Paranhos Júnior foi o único diplomata a ter papel de protagonista no processo negociador das fronteiras de um país de dimensão continental, e a ver consagrado na História o reconhecimento da nação numa narrativa de valor sobre a sua obra, o que o tornou patrimônio nacional.

Em seu ensaio Rio Branco, definidor dos valores nacionais, Rubens Ricupero cita Gilberto Freyre, em Ordem e Progresso, segundo o qual, sob a direção do Barão, o Itamaraty teria deixado de ser instituição puramente diplomática para transformar-se em sistema de organização e definição de valores superiormente nacionais. ${ }^{10}$

Esse patrimônio diplomático, que ainda hoje contribui para a manutenção da paz e da segurança na região e das tradições regionais a serviço do entendimento,

9 PEREIRA, Manoel Gomes (Org.). Barão do Rio Branco, 100 Anos de Memória. Brasília: Fundação Alexandre de Gusmão, 2012.

10 In: CARDIM, Carlos Henrique; ALMINO, João (Org.). Rio Branco, a América do Sul e a modernização do Brasil. Brasília: FUNAG, 2002. 
da cooperação e da boa vizinhança, poderia ter-lhe valido o Prêmio Nobel da Paz, que tampouco foi conferido, mais tarde, a Gandhi, líder da independência e do movimento pacifista na Índia. A dimensão do legado desses dois vultos na defesa de valores universais do direito e da paz permanece com o reconhecimento maior dos seus próprios povos e da História. Se as condições geopolíticas da América do Sul tornam o continente uma das poucas regiões do mundo sem conflitos internacionais, esse resultado não é acidental; muito se deve à construção das condições de estabilidade hemisféricas que passou pela obra fecunda de José Maria da Silva Paranhos Júnior, o Barão do Rio Branco. Tais condições - conviria frisar - não são, assim, fruto do acaso ou de circunstâncias fortuitas, mas de uma construção diplomática, de um paradigma regional de política externa.

O multilateralismo e a igualdade dos Estados

Outro personagem que se destaca nessa narrativa de valores da História Diplomática do Brasil é Rui Barbosa, ${ }^{11}$ sobretudo pelo papel que desempenhou na consolidação do conceito da igualdade soberana dos Estados durante a II Conferência de Paz da Haia, em 1907. ${ }^{12}$ A participação do Brasil marca o compromisso do País com o multilateralismo e com a defesa de princípios que têm inspirado a política externa brasileira e assegurado sua consistência e coerência, além de contribuir para o seu prestígio internacional. A firmeza e competência com que o Brasil defendeu suas posições consolidaram a igualdade entre os Estados como paradigma - hoje inscrito na Constituição, em seu art. $4^{\circ}$. O maior reconhecimento internacional desse princípio se deu, em 1945, com sua inclusão na própria Carta de São Francisco, que estabeleceu a Organização das Nações Unidas.

A alcunha de Águia de Haia, que recebeu da imprensa, refletiu seu desempenho parlamentar na Conferência, sobretudo no tratamento da questão da igualdade jurídica entre os Estados. Mas Rui Barbosa, além da defesa da soberania, distinguiu-se por sua contribuição nos debates em favor da democratização do sistema internacional, do princípio do mare liberum e também do aperfeiçoamento das normas do direito internacional humanitário.

\section{Segundo Celso Lafer,}

a ação de Rui na Haia é não só congruente com a sua prática política e a relevância de seu legado no plano interno, como também representou, no plano externo, o fazer diplomático

11 CARDIM, Carlos Henrique. A raiz das coisas. Rui Barbosa: o Brasil no Mundo. Rio de Janeiro: Civilização Brasileira, 2007.

12 CHDD. A Conferência de Paz da Haia 1907: A correspondência telegráfica entre o Barão do Rio Branco e Rui Barbosa. Rio de Janeiro: Fundação Alexandre de Gusmão, 2014. 
precursor do tema e do processo da democratização do sistema internacional $(2001$, p. 70$){ }^{13}$

Essa participação visionária, altiva e conceitualmente sólida marca o compromisso do Brasil com o multilateralismo, que ganha então densidade e visibilidade, quando a diplomacia brasileira assume atitude firme em favor da consolidação pela comunidade internacional do princípio vestfaliano da igualdade dos Estados perante a lei internacional. Rui Barbosa foi, de fato, um pioneiro da diplomacia multilateral. O multilateralismo corresponde à crença num sistema de interação estatal em que cada membro busca estabelecer relações com o conjunto dos demais, em vez de agir unilateralmente ou priorizar apenas ações bilaterais. Não só representa a face internacional do estado democrático de direito, como se tornou também instrumento global do desenvolvimento sustentável, conceito consagrado na Conferência do Rio, em 1992, com o concurso e a liderança brasileira.

O Brasil se destaca também no cenário internacional por sua condição de membro fundador da Organização das Nações Unidas e de muitos organismos internacionais, bem como por sua ativa participação nessas instituições. Recorde-se ainda a introdução da agricultura nas disciplinas do GATT e a criação da Organização Mundial do Comércio (OMC), em 1995. A consolidação e a expansão do Direito Internacional Público se tem beneficiado dos esforços brasileiros tanto na defesa e formulação de conceitos, quanto na sua correta observância e aplicação. O Brasil tem dado contribuição notável ao processo de codificação e desenvolvimento do jus gentium. A diplomacia brasileira concorreu historicamente para a defesa de princípios, valores e interesses que representam a identidade e o legado do País em suas relações externas.

Com base na estrita observância do Direito Internacional e no princípio da boa vizinhança e da não-intervenção (paradigmas defendidos por José Bonifácio e consolidados pelo Barão do Rio Branco); da defesa da soberania e igualdade dos Estados, da liberdade dos mares e do direito internacional humanitário (Rui Barbosa, em Haia); do direito do homem à liberdade (Joaquim Nabuco, na luta contra a escravidão); do liberalismo e democracia (Oswaldo Aranha, no contexto da Segunda Guerra Mundial), ${ }^{14}$ do direito ao desenvolvimento (Juscelino Kubistchek, na proposta de uma Operação Panamericana - OPA), ${ }^{15}$ da autonomia em política externa, da justiça numa nova ordem

13 LAFER, Celso. A identidade internacional do Brasil e a Politica Externa Brasileira. São Paulo: Perspectivas, 2001.

14 ALMEIDA, Paulo Roberto de; ARAUJO, João Hermes Pereira de. Oswaldo Aranha: na continuidade do estadismo de Rio Branco. In: PIMENTEL, José Vicente de Sá (Org.). Pensamento diplomático brasileiro: formuladores e agentes de política externa. 1750-1964. Brasília: Fundação Alexandre de Gusmão, 2013. p. 669-674.

15 CHDD. Operação Pan-Americana. Cadernos do CHDD, Rio de Janeiro, a. 6, n. 10, 2007. 
internacional (Afonso Arinos e San Tiago Dantas), ${ }^{16}$ da denúncia ao congelamento do poder e ao colonialismo (Araújo Castro), ${ }^{17}$ a diplomacia brasileira constrói um sólido legado de ideias e valores, que está presente também na negociação do regime dos mares e no próprio conceito de desenvolvimento sustentável.

\section{A Convenção do Direito do Mar}

A Convenção das Nações Unidas sobre o Direito do Mar, concluída em Montego Bay, Jamaica, em 10 de dezembro de 1982, representa extraordinário patrimônio político no contexto das relações internacionais do pós-guerra. Constitui exemplo das possibilidades da governança global baseada num multilateralismo robusto, voltado para o desenvolvimento sustentável, a paz e a segurança internacional. Após a Carta das Nações Unidas, talvez seja o instrumento mais complexo e abrangente negociado pela comunidade internacional.

O Brasil foi um dos países que lideraram o processo de negociação e de busca da construção de um consenso que muitos acreditavam difícil, senão impossível, situação agravada pelas reservas que marcaram a posição dos EUA e da então União Soviética. A Convenção simboliza em sua gênese e em seus propósitos muitos dos princípios e ideais presentes na evolução dessa narrativa de valores das relações internacionais e do pensamento diplomático brasileiro. ${ }^{18}$

Reflete também o "esforço para traduzir necessidades internas em possibilidades externas - na expressão de LAFER (2001, op. cit, p. 90) - ampliando o poder de controle do país sobre o seu destino, na lógica diplomática de um nacionalismo de fins". ${ }^{19}$ A agenda da diplomacia sofre alterações, mas não necessariamente os princípios fundamentais da política externa, os que nos acompanham desde o início de nossa História, em especial o da busca, mediante a negociação pragmática e a afirmação dos valores

16 DANTAS, San Tiago. Politica externa independente. Brasília: FUNAG, 2011.

17 VARGAS, João Augusto Costa. Um mundo que também é nosso. O pensamento e a trajetória diplomática de Araújo Castro. Brasília: FUNAG, 2013.

18 O Governo brasileiro ratificou a Convenção das Nações Unidas sobre o Direito do Mar em 22 de dezembro de 1988 e, pelo Decreto n. 1.530, de 22 de junho de 1995, declarou sua entrada em vigor para o Brasil em 16 de novembro de 1994, de conformidade com o seu art. 308, parágrafo 1.

19 Hélio Jaguaribe, em sua análise sobre o significado do nacionalismo no Brasil, definiu-o nos seguintes termos: "O nacionalismo não é imposição de nossas peculiaridades, nem simples expressão de características nacionais. É, ao contrário, um meio para atingir um fim: o desenvolvimento.” Argumentou ser “indispensável elucidar todos os equívocos tendentes a confundir com o nacionalismo o fato de serem nacionais os agentes ou recursos empregados para a obtenção de um fim qualquer." Nesse sentido, cabia distinguir os dois nacionalismos. Enquanto o de meios se prende à negação do capital estrangeiro, o nacionalismo de fins, ao reconhecer que seu propósito é o desenvolvimento, procura utilizar-se "de todos os meios apropriados, seja qual for a origem dos agentes, desde que, nas condições concretas, se revelem os mais eficazes." In: JAGUARIBE, H. O nacionalismo na atualidade brasileira. 3. ed. Brasília: FUNAG, 2013. p. 69-70. 
nacionais, de condições para o desenvolvimento e para a ampliação da autonomia do País na execução de sua política externa.

A ação diplomática brasileira nas tratativas que levaram à conclusão exitosa da Convenção do Mar correspondeu a um momento de afirmação externa dos objetivos e valores nacionais, bem como dos padrões de conduta do Estado em sua dimensão global.

A diplomacia brasileira: o regime dos mares

A Convenção de Montego Bay é expressão maior do multilateralismo num momento em que se buscava novo ordenamento internacional mais justo e equitativo. Negociada durante mais de nove anos, a Convenção constitui o principal arcabouço político e jurídico para regulamentar o uso dos oceanos. Conhecida como "A Constituição do Mar", normatiza todos os aspectos do universo marítimo, inclusive delimitação das fronteiras, regulamentos ambientais, investigação científica, comércio e resolução dos conflitos internacionais envolvendo questões marinhas. A Convenção é, ademais, importante fator de sustentabilidade dos espaços oceânicos.

Por sua dimensão territorial e extensão de suas costas, o Brasil empenhouse na elaboração de regime jurídico internacional que salvaguardasse e protegesse os interesses nacionais no aproveitamento do que se conhece como a "Amazônia Azul" pela escala e diversidade de suas riquezas. A proteção dos interesses brasileiros no mar cresceu em importância a partir das descobertas de hidrocarbonetos na camada do Pré-Sal, cuja exploração, já em curso, depende, no longo prazo, da permanência de fatores que garantam sua viabilidade econômica e tecnológica.

A Convenção do Mar definiu os conceitos dos espaços marítimos (Águas Interiores, Mar Territorial, Zona Contígua, Zona Econômica Exclusiva, Plataforma Continental, Alto-mar e Fundos Marinhos) e criou três órgãos internacionais para assegurar o cumprimento dos seus dispositivos (Autoridade Internacional para os Fundos Marinhos, sediada em Kingston, Jamaica; ${ }^{20}$ Tribunal Internacional sobre Direito do Mar, sediado em Hamburgo, Alemanha; Comissão dos Limites da Plataforma Continental, instalada na sede das Nações Unidas, em Nova Iorque).

20 Em dezembro de 2013, o Brasil apresentou à Autoridade Internacional dos Fundos Marinhos (ISBA) proposta de Plano de Trabalho para Exploração de Crostas Ferromanganesíferas Ricas em Cobalto. O Plano foi aprovado por ocasião da $20^{\mathrm{a}}$ Sessão da ISBA, em julho passado. O Contrato de Exploração entre a ISBA e o Brasil deverá ser assinado em 2015. O Plano de Trabalho reveste-se de importância estratégica, pois assegura a presença brasileira na Elevação de Rio Grande (ERG), região de grande potencial mineral, localizada além das águas jurisdicionais brasileiras (AJB), em frente ao Rio Grande do Sul. Com o início das atividades do Plano de Trabalho, o Brasil firma-se entre os países que desenvolvem atividades de exploração na área internacional dos fundos marinhos. Foi o primeiro plano de trabalho aprovado de um país da América Latina e Caribe. (fonte: DMAE, MRE). 
Por seu impacto no regime do direito do mar, inclusive do ponto de vista da preservação do meio ambiente, a codificação de tais conceitos tem servido de referência até mesmo para Estados não signatários da Convenção. Além disso, o princípio nela consagrado do uso pacífico dos mares e oceanos inspirou a proposta brasileira submetida, em maio de 1986, ao Secretário-Geral da ONU, e que geraria, no mesmo ano, a Declaração de uma Zona de Paz e Cooperação do Atlântico Sul (ZOPACAS). ${ }^{21}$ A consolidação da Zona de Paz, objeto de sete reuniões ministeriais dos países que dela fazem parte, duas das quais no Brasil, dão a medida da importância estratégica do Atlântico Sul e da capacidade da diplomacia brasileira de gerar novas geometrias internacionais voltadas à promoção da paz, da cooperação e da segurança. ${ }^{22}$

A iniciativa da coletânea Reflexões sobre a Convenção do Direito do Mar, publicada pela FUNAG e antes referida e que pode ser consultada no portal da Fundação, ajuda a suprir lacuna bibliográfica existente sobre tema tão importante e estratégico num momento de alto simbolismo do espírito de compreensão e cooperação internacional e do significado histórico que marcaram a conclusão do Tratado do Direito do Mar.

Na apresentação do livro, prestei homenagem a instituições e personalidades, dentro e fora da Casa de Rio Branco, que se dedicaram a estudos, pesquisas e debates, que tanto contribuíram para a formulação da política brasileira nesse vasto e estratégico campo multidisciplinar para o qual convergem interesses e ações públicas e privadas. Recordei a tradição do Itamaraty na área do direito do mar, bem como o fato de ser o então Ministro de Estado das Relações Exteriores, Embaixador Luiz Alberto de Figueiredo Machado, considerado parte dela. Ressaltei personalidades como os Embaixadores Carlos Calero Rodrigues e Ramiro Saraiva Guerreiro, que muito contribuíram para estabelecêla. Ambos são reconhecidos como principais formuladores das posições brasileiras e destacados negociadores da Convenção do Mar.

Jovens diplomatas colaboraram no processo de formulação das políticas por meio de pesquisas contidas em trabalhos do Curso de Altos Estudos do Instituto Rio Branco, publicados também pela FUNAG e que, ainda hoje, constituem referência necessária à análise e ao debate sobre diferentes aspectos da temática marinha. ${ }^{23}$

No campo jurídico, o Professor Vicente Marotta Rangel, que recebeu da Faculdade de Direito da USP justa homenagem por sua reconhecida contribuição ao Direito

21 Resolução n. A/RS/41/11, de 27 de outubro de 1986.

22 CORTES, Octávio Henrique Dias Garcia. A política externa do Governo Sarney. Brasília: FUNAG, 2010. p. 188. A proposta foi anunciada no discurso de abertura pelo Chanceler Roberto de Abreu Sodré da XLI Sessão Ordinária da Assembleia Geral das Nações Unidas. Vide também CORRÊA, Luiz Felipe de Seixas. O Brasil nas Nações Unidas, 1946-2011. Brasília: FUNAG, 2012. p. 582.

23 Vide MOREIRA LIMA, Sergio Eduardo. Apresentação. In: BEIRÃO, André Panno et al. Reflexões sobre a Convenção do Direito do Mar. p. 9. 
do Mar, que inclui também a formação de outros tantos especialistas na matéria, tornouse um dos maiores conhecedores do tema no Brasil. Destacou-se ainda por seu valioso concurso à delegação que negociou a Convenção durante uma década. Seus méritos, além da ação da diplomacia brasileira, levaram-no à eleição como juiz do Tribunal Internacional do Direito do Mar. Outro jurista de destaque no processo foi Antônio Augusto Cançado Trindade, também Consultor Jurídico do Itamaraty e atualmente Ministro da Corte Internacional de Justiça da Haia.

No âmbito da Marinha, muitos foram aqueles cujo estudo e conselho sobre aspectos técnicos ou estratégicos influíram junto a formuladores e negociadores brasileiros. O Itamaraty e a Marinha desenvolveram perfeita colaboração na avaliação e no tratamento do processo negociador da Convenção, inclusive no âmbito da Comissão Interministerial de Recursos do Mar. Cabe destacar a importância do papel da Marinha e daqueles que, dentro daquela Força, tanto se dedicaram e se dedicam à reflexão sobre os desafios do mar e os interesses brasileiros.

No século XXI, a Convenção das Nações Unidas para o Direito do Mar deve dar a contribuição que lhe cabe na defesa do ecossistema da Terra. A Declaração Final da Conferência das Nações Unidas sobre Desenvolvimento Sustentável (RIO+20) considerou oceanos e águas costeiras fundamentais para a sobrevivência do planeta. Ressaltou a importância da conservação e utilização sustentável do mar, inclusive para a erradicação da pobreza, segurança alimentar e trabalho decente, protegendo, ao mesmo tempo, a biodiversidade, o ambiente marinho e remediando os impactos da mudança do clima.

No documento, a comunidade internacional reconheceu o papel da Convenção para promover o desenvolvimento sustentável, bem como a importância da sua adoção quase universal pelos Estados, instando todos os Estados-Membros a implementar plenamente suas obrigações perante a Convenção.

Limites Exteriores da Plataforma Continental do Brasil conforme o Direito do Mar

No regime jurídico criado pela Convenção do Direito do Mar, a questão do estabelecimento dos limites exteriores da plataforma continental reveste-se de especial importância para um país de dimensão territorial costeira como o Brasil, dada a possibilidade de sua extensão além das 200 milhas e da expressão econômica do reconhecimento de tal reivindicação, caso a submissão seja acolhida pelo órgão competente criado pela Convenção. ${ }^{24}$

24 A Convenção do Direito do Mar, no art. 4 do seu anexo II, dispõe que: "Quando um Estado costeiro tiver intenção de estabelecer, de conformidade com o art. 76, o limite exterior da sua plataforma continental além 
No direito brasileiro, ${ }^{25} \mathrm{o}$ conceito de plataforma do Estado costeiro abrange o leito e o subsolo das áreas marinhas além de seu mar territorial, até, em princípio, uma distância de 200 milhas marítimas. No entanto, prevê sua extensão em conformidade com o disposto no art. 76 da Convenção das Nações Unidas. ${ }^{26}$ Tal prerrogativa permite ao estado costeiro reivindicar extensão maior de até 350 milhas da linha de base, a partir da qual se mede a largura do mar territorial. ${ }^{27}$

O Brasil submeteu informações sobre a extensão de sua plataforma continental além das 200 milhas marítimas ao órgão técnico e científico internacional estabelecido pela Convenção - a Comissão de Limites da Plataforma Continental (CLPC). O Governo brasileiro busca afirmar direitos soberanos sobre os recursos do espaço marítimo de, pelo menos, cerca de $960 \mathrm{mil} \mathrm{km}^{2}{ }^{28} \mathrm{Com}$ isso, o Brasil determinaria

de 200 milhas marítimas, apresentará à Comissão de Limites da Plataforma Continental da ONU, logo que possível, mas em qualquer caso dentro dos 10 anos seguintes à entrada em vigor da presente Convenção para o referido Estado, as características de tal limite, juntamente com informações científicas e técnicas de apoio..."

25 O art. 11 da Lei n. 8.617, de 4 de janeiro de 1993, que reflete o disposto no art. 76 da Convenção, estabelece que: "A plataforma continental do Brasil compreende o leito e o subsolo das áreas submarinas que se estendem além do seu mar territorial, em toda a extensão do prolongamento natural de seu território terrestre, até o bordo exterior da margem continental, ou até uma distância de duzentas milhas marítimas das linhas de base, a partir das quais se mede a largura do mar territorial, nos casos em que o bordo exterior da margem continental não atinja essa distância. Parágrafo único. O limite exterior da plataforma continental será fixado de conformidade com os critérios estabelecidos no art. 76 da Convenção das Nações Unidas sobre o Direito do Mar, celebrada em Montego Bay, em 10 de dezembro de 1982.

26 Art. 76. Definição da Plataforma Continental. 1. A plataforma continental de um Estado costeiro compreende o leito e o subsolo das áreas submarinas que se estendem além do seu mar territorial, em toda a extensão do prolongamento natural do seu território terrestre, até ao bordo exterior da margem continental, ou até uma distância de 200 milhas marítimas das linhas de base a partir das quais se mede a largura do mar territorial, nos casos em que o bordo exterior da margem continental não atinja essa distância. (...) 5. Os pontos fixos que constituem a linha dos limites exteriores da plataforma continental no leito do mar (...) devem estar situados a uma distância que não exceda 350 milhas marítimas da linha de base a partir da qual se mede a largura do mar territorial (...). 6. Não obstante as disposições do parágrafo $5^{\circ}$, no caso das cristas submarinas, o limite exterior da plataforma continental não deve exceder 350 milhas marítimas das linhas de base a partir das quais se mede a largura do mar territorial (...). 7. O Estado costeiro deve traçar o limite exterior da sua plataforma continental, quando esta se estender além de 200 milhas marítimas das linhas de base a partir das quais se mede a largura do mar territorial, unindo, mediante linhas retas, que não excedam 60 milhas marítimas, pontos fixos definidos por coordenadas de latitude e longitude. 8. Informações sobre os limites da plataforma continental, além das 200 milhas marítimas das linhas de base a partir das quais se mede a largura do mar territorial, devem ser submetidas pelo Estado costeiro à Comissão de Limites da Plataforma Continental, estabelecida de conformidade com o Anexo II. (...)."

27 Vide também FIGUEIRÔA, Christiano Sávio Barros. Limites exteriores da plataforma continental do Brasil conforme o direito do mar. Brasília: FUNAG, 2014. p. 32.

28 LEPLAC - Plano de Levantamento da Plataforma Continental. O Brasil desenvolve processo de revisão da proposta de delimitação de sua plataforma continental além das 200 milhas marítimas (Plataforma Continental Estendida - PCE), apresentada em maio de 2004 à Comissão de Limites da Plataforma Continental (CLPC) das Nações Unidas. A CLPC não endossou, em suas recomendações, publicadas em 2007, parte $\left(190.000 \mathrm{~km}^{2}\right)$ da área total pleiteada pelo Brasil. O Grupo de Trabalho encarregado da elaboração da submissão revista, integrado pelo Itamaraty, trabalha na submissão parcial (dedicada à parte sul), para posterior encaminhamento à CLPC. A extensão da Plataforma Continental tem importância fundamental 
"seu último limite jurídico - a plataforma continental - para concluir a obra do traçado definitivo da base física da Nação." 29

A título de comparação, a área reivindicada pelo Brasil além das 200 milhas marítimas corresponde a mais de $10 \%$ da superfície terrestre do País, maior que o espaço de todo o Estado de São Paulo e a região Sul do Brasil. As recentes descobertas de significativas jazidas de petróleo e gás natural na camada pré-sal, na plataforma continental brasileira dentro das 200 milhas, reforçam o sentido estratégico dessa iniciativa. ${ }^{30}$

O Brasil foi o segundo país a apresentar proposta de bordo exterior de sua plataforma continental à CLPC, em 2004. O interesse brasileiro na definição dos limites exteriores da plataforma decorre das características do seu litoral e relevo submarino. Com 7,367 mil km de costa atlântica, o Brasil conta, segundo Marotta Rangel, com praticamente $1 \mathrm{~km}$ de litoral para cada $1,3 \mathrm{~km}$ de fronteira terrestre. ${ }^{31}$

A vastidão desse litoral cria ao mesmo tempo a oportunidade para a pesquisa científica, a exploração e o aproveitamento dos recursos dos espaços marítimos sujeitos à jurisdição brasileira e o desafio de assegurar sua proteção adequada, em termos ambientais e de segurança. Além de extenso, o litoral brasileiro caracteriza-se por estar aberto a amplas áreas de alto-mar no oceano Atlântico. Geograficamente, o Brasil não se defronta com nenhum Estado costeiro com o qual possa ter problemas de delimitação de plataforma continental e outros espaços marítimos. Apesar de fazer fronteira com quase todos os países da América do Sul, tem costas adjacentes apenas com o Uruguai e com a França (Guiana Francesa). O Brasil conta, ainda, com margem continental de tipo divergente, originada do processo de separação entre a África e a América do Sul e da sedimentação de elementos trazidos do território terrestre. Esse tipo de margem continental é o que orientou quase todo o regime acordado na Convenção do Direito do Mar para o reconhecimento de direitos soberanos sobre os recursos da plataforma além das 200 milhas, o que facilita, pelo menos em tese, a aplicação de suas regras.

A definição dos limites exteriores da plataforma continental do Brasil em exame representa o mais importante procedimento de delimitação do País desde Rio Branco. Ao contrário das negociações de fronteira do período do Barão, solucionadas

para o Brasil, pelo potencial que representa em termos de aproveitamento dos recursos minerais (petróleo, gás natural, fosforitas, carvão, enxofre, nódulos e sulfetos polimetálicos, crostas ferromanganesíferas ricas em cobalto, hidratos de gás, entre outros) presentes na área. (Fonte: DMAE, MRE).

29 MACHADO, Luiz Alberto Figueiredo. A plataforma continental brasileira e o direito do mar: considerações para uma ação política. 2000. Tese. (XL Curso de Altos Estudos) - Ministério das Relações Exteriores, Instituto Rio Branco, Brasília, 2000. p. 8.

30 FIGUEIRÔA, Christiano Sávio Barros. Limites exteriores da plataforma continental do Brasil conforme o direito do mar. Brasília: FUNAG, 2014. p. 32.

31 FIGUEIRÔA, Christiano Sávio Barros. Limites exteriores da plataforma continental do Brasil conforme o direito do mar. Brasília: FUNAG, 2014. p. 33. 
por negociações bilaterais ou arbitragem, a fixação do limite exterior da plataforma continental estendida ocorre pela via do multilateralismo: o Brasil se defronta não com outro Estado com pretensões territoriais concorrentes, mas com órgão internacional de peritos independentes que estudam a submissão do País à luz dos critérios estabelecidos pela CLPC.

Os agentes do Estado brasileiro envolvidos na preparação e defesa da proposta à CLPC seriam, nas palavras de um deles, "os bandeirantes das longitudes salgadas", ${ }^{32}$ a contribuírem, no século XXI, para consolidar nova expansão das áreas sob jurisdição do Brasil. É bem verdade que se trata de uma jurisdição sob as condicionantes previstas na própria Convenção e que obriga o País às responsabilidades decorrentes dos princípios como o do desenvolvimento sustentável e outros contemplados no Direito do Mar.

Não pretendo estender-me além do razoável, mas recomendo, pela qualidade e atualidade da análise, a leitura de "Limites Exteriores da Plataforma Continental do Brasil conforme o Direito do Mar", de autoria do Conselheiro Christiano Sávio Barros Figueirôa, que a FUNAG publicou em 2014. A obra tem sua origem na tese submetida, em 2013, à Banca Examinadora do Curso de Altos Estudos do Instituto Rio Branco e aprovada com louvor. O trabalho examina o processo de definição dos limites exteriores da plataforma continental do Brasil de acordo com o regime estabelecido na Convenção do Direito do Mar.

Figueirôa estuda a evolução do conceito da plataforma continental no Direito Internacional, com foco nos critérios para estabelecer seu limite exterior e no empenho do governo brasileiro em ver reconhecidos direitos soberanos sobre a plataforma continental além das 200 milhas marítimas.

A edição do livro é parte da celebração do $20^{\circ}$ aniversário da entrada em vigor no Brasil da Convenção do Mar e se dá num momento de debate e expectativa com relação ao aproveitamento de grandes riquezas da plataforma continental brasileira. Essa circunstância, como observou Antonio Augusto Cançado Trindade, que apresenta o livro, aumenta o interesse nesse espaço marítimo como expressão da estratégia nacional de desenvolvimento sustentável.

\section{A política do Brasil no Ártico}

Outro tópico que merece reflexão é o tratamento da questão do Ártico. Até o momento, o interesse brasileiro tem-se concentrado na Antártica, o que é natural, dadas

32 FIGUEIRÔA, Christiano Sávio Barros. Limites exteriores da plataforma continental do Brasil conforme o direito do mar. Brasília: FUNAG, 2014. p. 34. 
a proximidade geográfica e sua influência climática e ictiológica. No entanto, o degelo no Ártico e suas consequências climáticas, ambientais e econômicas, inclusive para novas rotas de transporte marítimo, apontam a oportunidade de o Brasil criar condições de ir além de sua atual perspectiva antártica. A importância do Ártico para o País e para o mundo tende a crescer e justifica a definição de prioridades e eventual inclusão da região em sua Estratégia Nacional.

A título de subsídio à pesquisa, os seguintes objetivos para a ação brasileira poderiam ser considerados:

1) Adesão ao Tratado de Spitsbergen (Svalbard), ${ }^{33}$ como forma de aproximar o Brasil dos interesses da região e dos países ali presentes.

2) Diálogo com países membros do Conselho do Ártico com vistas a promover as credenciais e legitimar eventual pleito de entrada no Conselho do Ártico como membro observador permanente.

3) Cooperação e acompanhamento dos efeitos da mudança do clima na região, das condições de aproveitamento dos recursos e da preservação da biodiversidade.

4) Promoção da pesquisa científica no Ártico por meio da cooperação bilateral, e eventual integração no programa antártico, inclusive com a avaliação da possibilidade de implantação de bases de pesquisa no local.

5) Reflexão sobre a conveniência de integrar assuntos árticos às competências da CONANTAR.

As principais questões atinentes à região são tratadas diretamente pelos países costeiros do Ártico: Estados Unidos, Canadá, Dinamarca, Islândia, Noruega e Rússia, com participação eventual da Finlândia e da Suécia. Ao contrário do que ocorre na Antártica, prevalece na região ártica percepção baseada na soberania. Os países árticos possuem um Conselho para discutir seus interesses dentro dessa perspectiva.

33 O Tratado de Spitsbergen (Svalbard) é um instrumento multilateral, firmado em Paris em 1920. Atualmente conta com quarenta Estados-parte, inclusive, da América Latina (Argentina, Chile e Venezuela). O Tratado reconhece a soberania limitada da Noruega sobre esse arquipélago, localizado no extremo Mar do Norte, em troca da faculdade de explorar recursos naturais e realizar pesquisas científicas naquele território. O tratado também resguarda o meio ambiente da região, o direito de não discriminação e o uso de aparatos militares regionais. Além da Rússia, que possui comunidades vivendo em Svalbard (denominação norueguesa), China e Índia têm realizado ali experiências científicas, inclusive voltadas para o estudo do degelo nas montanhas do Himalaia. 
A importância da região cresce pari passu aos efeitos da mudança do clima mundial. Com o aumento da temperatura global e o derretimento das calotas polares, a região assume relevância no cenário global, devido a fatores econômicos, ambientais e estratégicos. Os econômicos estão relacionados às possibilidades de expansão da exploração de recursos naturais no Ártico. A dimensão estratégica é reforçada pela possibilidade de utilização de rotas marítimas regionais ao longo de todo o ano. Justificar-se-ia, assim, um novo olhar para esses aspectos, tendo como pano de fundo a cooperação internacional e o desenvolvimento sustentável da região.

Solução pacífica das controvérsias, manutenção da paz e da segurança internacional

O ano de 2014 foi especial para a Convenção do Direito do Mar pelas razões expostas, entre as quais o $20^{\circ}$ aniversário de sua entrada em vigor no Brasil, o centenário da Escola de Guerra Naval e a inauguração ali do primeiro curso de mestrado em Estudos Marítimos, aberto aos civis, além do lançamento de quatro livros sobre o tema, dois dos quais editados pela FUNAG.

No plano internacional, o período foi marcado pela declaração do Presidente dos Estados Unidos da América, em seu tradicional pronunciamento aos cadetes da Academia Militar de West Point, na qual comenta que os EUA não se devem eximir do reconhecimento de regras que se aplicam aos demais países e sugere que teria sido mais conveniente aderir à Convenção de maneira a poder melhor lidar com questões geopolíticas, como as do Sul do Mar da China.

Nas palavras do Presidente Barack Obama: "A influência americana é sempre mais forte quando lideramos pelo exemplo. Não podemos nos eximir das regras que se aplicam a todos (...). Não podemos tentar resolver problemas no Mar do Sul da China, quando nos negamos a garantir que a Convenção do Direito do Mar seja ratificada pelo próprio Senado dos Estados Unidos, apesar do fato de nossos principais líderes militares afirmarem que o tratado aumenta nossa segurança nacional". Concluiu que, "isso não representa liderança; mas sim, retrocesso". ${ }^{34}$

$34 \quad$ Eis a íntegra do parágrafo original do discurso: "You see, American influence is always stronger when we lead by example. We can't exempt ourselves from the rules that apply to everybody else. We can't call on others to make commitments to combat climate change if a whole lot of our political leaders deny that it's taking place. We can't try to resolve problems in the South China Sea when we have refused to make sure that the Law of the Sea Convention is ratified by our United States Senate, despite the fact that our top military leaders say the treaty advances our national security. That's not leadership; that's retreat. That's not strength; that's weakness. It would be utterly foreign to leaders like Roosevelt and Truman, Eisenhower and Kennedy." THE WHITE HOUSE. Office of the Press Secretary. Remarks by the president at the United States Military Academy Commencement Ceremony. 28 de maio de 2014. Disponível em: <http:// www.whitehouse.gov/the-press-office/2014/05/28/remarks-president-united-states-military-academycommencement-ceremony>. 
Adeclaração do Presidente dos EUAnão deixa de representar reconhecimento da importância de princípios e valores que historicamente o Brasil tem defendido e que tiveram expressão na liderança exercida pela diplomacia brasileira e de outros países nas Nações Unidas em prol da negociação e da conclusão da Convenção do Direito do Mar.

Conclusão

A reflexão que se fez no I Congresso Brasileiro de Direito do Mar na USP sobre a Convenção e seus desdobramentos, na presença de ilustres professores e juristas, conceituados juízes brasileiros e estrangeiros e outros representantes do Tribunal do Direito do Mar, contribuirá para a percepção da importância deste marco histórico da diplomacia multilateral, monumento ao espírito de compreensão e cooperação internacional.

Concorrerá ainda para avaliar a participação do Brasil no processo que levou à conclusão da Convenção de Montego Bay, bem como para aprofundar uma perspectiva dos interesses brasileiros na matéria, inclusive a partir dos livros editados sobre o tema. Talvez o maior mérito do evento que homenageou Marotta Rangel tenha sido o de enriquecer a visão crítica a respeito da responsabilidade de todos os Estados, partes e ainda não partes do Tratado, para com o bem-estar e o futuro da humanidade.

O Direito do Mar constitui, ainda hoje, um dos temas centrais da política externa brasileira e motivo de orgulho para seus formuladores e executores, que lograram tornar a Convenção o principal arcabouço político e jurídico para regular o uso dos mares e oceanos de forma sustentável. A participação ativa no processo negociador ilustra a narrativa de valores que acompanha o pensamento diplomático brasileiro e que tem hoje no art. $4^{\circ}$ da Constituição federal sua fonte de inspiração.

A tentativa de interpretação axiológica da História Diplomática fortalece a identidade do Brasil, a liderança moral e intelectual que deve exercer em conformidade com suas tradições e convicções. Permite melhor distinguir os atributos do poder brando (soft power) e de sua contribuição para um Estado livre e soberano, respeitado por seus valores democráticos, que garantem coerência e consistência à diplomacia e à preservação de suas credenciais no mundo.

Essa perspectiva distinta de análise das relações internacionais estimula também a reflexão sobre liberdade e justiça, democracia e direito como fundamentos e fatores de legitimidade da governança global, da hierarquia de poderes e competências dentro da ordem internacional. Não deixa de surpreender o contraste entre valores e princípios considerados essenciais no plano nacional em países democráticos e sua ainda reduzida projeção externa. Num mundo que se globaliza, esse paradoxo torna-se cada vez mais perceptível como dilema moral e político que afeta a dignidade dos que são menos iguais e ameaça o sentido e o alcance do princípio da igualdade dos Estados perante a 
lei internacional, consagrada na Carta das Nações Unidas, e para o qual o Brasil tanto colaborou.

Brasília, abril de 2015.

\section{Referências}

ANJOS, João Alfredo dos. José Bonifácio, primeiro chanceler do Brasil. Brasília: Fundação Alexandre de Gusmão, 2008.

BEIRÃO, André Panno; ALVES PEREIRA, Antônio Celso. Reflexões sobre a Convenção do Direito do Mar. Brasília: Fundação Alexandre de Gusmão, 2014.

CARDIM, Carlos Henrique. A raiz das coisas. Rui Barbosa: O Brasil no mundo. Rio de Janeiro: Civilização Brasileira, 2007.

CARDIM, Carlos Henrique; ALMINO, João (Orgs.). Rio Branco a América do Sul e a modernização do Brasil. Brasília: FUNAG, 2002.

CHDD. A Conferência de Paz da Haia 1907: a correspondência telegráfica entre o Barão do Rio Branco e Rui Barbosa. Rio de Janeiro: Fundação Alexandre de Gusmão, 2014.

CHDD. Operação Pan-Americana. Cadernos do CHDD, Rio de Janeiro, a. 6, n. 10, 2007.

CORRÊA, Luiz Felipe de Seixas. O Brasil nas Nações Unidas, 1946-2011. Brasília: FUNAG, 2012.

CORTES, Octávio Henrique Dias Garcia. A política externa do Governo Sarney. Brasília: FUNAG, 2010 .

CORTESAO, Jaime. Alexandre de Gusmão. Brasília: Fundação Alexandre de Gusmão, 2011.

DANTAS, San Tiago. Politica externa independente. Brasília: FUNAG, 2011.

FIGUEIRÔA, Christiano Sávio Barros. Limites exteriores da plataforma continental do Brasil conforme o direito do mar. Brasília: FUNAG, 2014.

FONSECA, Gelson. A legitimidade e outras questões internacionais, poder e ética entre as nações. Paz e Terra: São Paulo, 1998.

JAGUARIBE, Helio. O nacionalismo na atualidade brasileira. Brasília: FUNAG, 2013.

LAFER, Celso. A identidade internacional do Brasil e a politica externa brasileira. São Paulo: Perspectivas, 2001.

MOREIRA LIMA, Sergio E. Diplomacia e academia: o IPRI, instrumento de política externa. Política Externa, São Paulo, v. 23, n. 2, p. 75-81, 2014.

PEREIRA, Manoel Gomes (Org.). Barão do Rio Branco, 100 Anos de memória. Brasília: Fundação Alexandre de Gusmão, 2012. 
PIMENTEL, José Vicente de Sá (Org.). Pensamento diplomático brasileiro: formuladores e agentes da política externa (1750-1950). Brasília: FUNAG, 2013.

RICUPERO, Rubens. Rio Branco: definidor de valores nacionais. In: Rio Branco a América do Sul e a Modernização do Brasil. Rio de Janeiro: EMC, 2002. p. 79-98.

THE WHITE HOUSE. Office of the Press Secretary. Remarks by the president at the United States Military Academy Commencement Ceremony. Disponível em: < http://www.whitehouse.gov/ the-press-office/2014/05/28/remarks-president-united-states-military-academy-commencementceremony>. Acesso em: 28 maio 2014.

VARGAS, João Augusto Costa. Um mundo que também é nosso. O pensamento e a trajetória diplomática de Araújo Castro. Brasília: FUNAG, 2013. 